\title{
OBITUARY
}

\section{In memory of Reginald Clift, 1929-2008}

\section{Bone Marrow Transplantation (2009) 43, 89-90;} doi:10.1038/bmt.2008.418

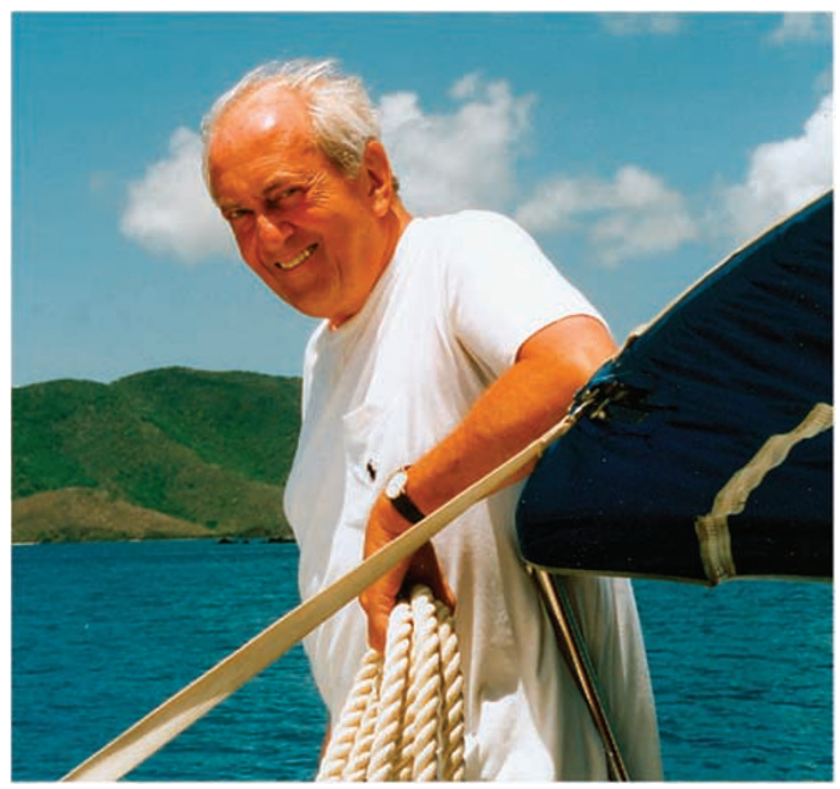

'In attempting to help write this memorial to Reginald Clift, I am reminded how much I miss him. In my medical career I have rarely written anything for publication that was not edited by him even if he was not a co-author. Reginald always had an uncanny knack of saying things in a more understandable manner with fewer words than most of us.' (Dean Buckner)

Reginald Clift was born in Pentyrch, Wales, and grew up and went to school in Cornwall. His formal training after high school was at the School of Medical Laboratory Technology, Royal Cornwall Infirmary, Truro, England. $\mathrm{He}$ did his national service in the Royal Air Force as a Laboratory Technician at the RAF Hospital in Wroughton and the RAF Institute of Pathology and Tropical Medicine in Halton. He worked as a Laboratory Technician at the Royal Cornwall Infirmary until he joined the British Colonial Service in 1953 and spent the next 14 years in Africa; first in Malawi (formerly Nyasaland) and then Kenya and Nigeria.

In Africa, he performed a variety of duties and acquired a range of skills not usually demanded of a technician. Not only did he direct the usual hematology, infectious disease, biochemistry and pathology services (including forensic work), but he also took charge of a production facility that made all rabies and smallpox vaccines used in a group of central African countries, a school for medical technicians and the manufacture of all i.v. fluids used throughout the country.

In Kenya, Reginald worked with the head and neck surgeon, Dr Peter Clifford, and the two became close friends and working partners. Reginald and Peter Clifford began treating patients with head and neck cancer (primarily lympho-epitheliomas) and Burkitt's lymphoma with nitrogen mustard or busulfan (myleran). They then explored the use of higher doses of nitrogen mustard with autologous marrow infusion, and the results of this study were published in the Lancet in 1961. Reginald was granted a US Public Health Service Research Fellowship, to study marrow cryopreservation at the Mary Imogene Bassett Hospital, in Cooperstown, New York, with Dr E Donnall (Don) Thomas. After 6 months of study, Reginald then returned to Africa and worked in Nigeria for the next 3 years, but ultimately had to leave because of the deteriorating political situation.

Don had moved from Cooperstown to the University of Washington in 1964 to set up a marrow transplant program. In 1967 Reginald was offered the position of supervising the clinical hematology and bacteriology laboratories that had been set up at the Seattle United States Public Health Hospital, one of the University of Washington's teaching hospitals, to support the marrow transplant team. By 1968 this team included Rainer Storb, Dean Buckner, Robert Epstein, Paul Neiman, Alex Fefer and E Donnall Thomas.

The following is how Don Thomas describes how Reginald got to the United States.

'In 1962 Louis Diamond, Professor of Pediatrics at Harvard Medical School, was a member of a medical team surveying medicine in Africa. When he returned to Boston he called me to say that he had met an unusual technician in Nairobi who wanted to come to Cooperstown to work with us on marrow transplantation. Since he had his own funding, we promptly agreed to take him. A few months later Reg, his wife Joyce, and their daughter arrived in Cooperstown. Reg proved to have knowledge in many areas of medicine, more like a physician than a technician. We had a most enjoyable time, professionally and socially. Nigel, their son, was born in Cooperstown.'

'In 1967 Reg wrote that white men were having a bad year in Africa, including fear for the safety of their families. He expressed an interest in joining the team in Seattle. I replied that we would be delighted to have him but that the only salary available was for a junior technician. It would take several months to get a suitable salary. In a few days Reg replied that he and family 
90

would arrive in Seattle in five days. Thus began our long, pleasant and productive association.'

It was clear from the beginning that Reginald was an integral part of the scientific marrow transplant team. Everyone on the team wished we could give him an honorary MD degree so he could formally take care of patients and take night call. His early work in Seattle focused on supportive care issues such as platelet and granulocyte transfusions and isolation and decontamination techniques in laminar air flow rooms. This was an era where effective antibiotics against pseudomonas and Staphylococcus aureus had yet to be developed. Thus, great attention was paid to preventing infections in immunosuppressed and granulocytopenic transplant recipients.

As the number of transplants grew and the number of papers published increased, Reginald took on the task of organizing the data. He became the master of using the personal computer for analyzing results of marrow transplantation. This did not come easily and for months we all wondered what Reginald was doing locked in his office behind closed doors. However, his early determination to master the relatively primitive programs at that time ultimately made him the most proficient data manager on the team. His ability to use his databases on large numbers of patients transplanted for AML and CML was responsible for major insights into SCT results in these diseases.

In the early 1990s, Reginald became a collaborator and friend of Guido Lucarelli in Pesaro and assisted him in setting up a computerized thalassemia transplant database. This was a productive relationship that persisted until very recently. Dr Lucarelli credited Reginald's work by making him a co-author on several scientific reports related to the outcomes of SCT for thalassemia.

Guido Lucarelli had the following to say about his relationship with Reginald:

'Rarely in advanced phases of life, do we meet with spontaneously born deep friendship. This happened to me in 1977 when I first met Reg in Dean Buckner's office. When the program of transplant in thalassemia had to be systematically structured in order to be statistically analyzed, Reg came to our center in Pesaro, back in 1988. Since then he loved to come to Pesaro with his wife Joyce in April and again in September almost every year. I could not have published anything relevant without Reg contributing in terms of criticism and statistical evaluation. Reg had an immense humanistic culture and a great sense of sarcasm. I learned to deal with him, occasionally falling victim to his English sense of humor. Once he told me, 'I cannot resist making a good joke, even if it hurts a friend like you.' He loved lions. He had billions of pictures of lions taken close-up by him. He himself was a great lion, unforgettable.'
'Many of his friends were not aware that Reg was an accomplished musician. He played the piano and the oboe and several other instruments. While in college he earned extra money playing piano in various night clubs. Both of his children became professional musicians. Anna, his daughter plays the cello and teaches. Nigel plays the viola and traveled with an orchestra for a time. When Anna graduated from the University of Washington as a music major part of the requirement was to present a concert of selected classical music. Reg rehearsed with her and accompanied her at the concert. Dottie and I attended the event and were so pleased not only with the wonderful music but also to see Reg glowing with pride.' (Don and Dottie Thomas)

Kris Doney remembers: 'During the early years of the Hutchinson Center, all the fellows-in-training quickly came to know Reg Clift. We respected and even feared his knowledge of transplantation and of medicine in general. He could always ask us a question that we could not answer. Most people thought he was a physician, and many probably still do. None of us was brave enough to ask what those impressive initials (F.I.M.L.S.) after his name signified.

After Reg semi-retired, he stopped by my office occasionally to catch up on the comings and goings of the faculty. After realizing we both had a connection to Cornwall and, therefore, knew the key ingredients needed to make a good pasty, we began to share our family stories. When Reg, Joyce and Martha (his beloved bulldog) moved to Atlanta, Georgia in 2007, our discussions continued until five weeks before his death when he called to say good-bye.

I will always remember Reg's twinkling eyes, his piercing questions and his acerbic wit, but most of all, I will always remember his friendship.'

Reginald continued to maintain the AML and CML databases even after he left the Fred Hutchinson Cancer Research Center in 1997 for semiretirement.

'Whenever I was scheduled to see patients with AML or CML in consultation after 1997, I e-mailed Reg asking for updates on transplantation outcomes for these diseases. Invariably, within hours, he responded with demographics, Kaplan-Meier curves, and other useful information - now no longer, sadly.' (Rainer Storb)

At the end of his career, Reginald was author or co-author of over 350 scientific publications related to marrow transplantation.

Rainer Storb

Fred Hutchinson Cancer Research Center, Seattle, WA, USA 